\title{
Aulas remotas, escolas vazias \\ e a carga de trabalho docente
}

\section{Online classes, empty schools}

and the teaching workload

\section{Clases remotas, escuelas vacías \\ y la carga del trabajo docente}

\section{GUSTAVO BRUNO BICALHO GONÇALVES}

Universidade Federal do Sul da Bahia, Itabuna-BA, Brasil.

\author{
JANE MARY DE MEDEIROS GUIMARÃES ${ }^{* *}$ \\ Universidade Federal do Sul da Bahia, Itabuna-BA, Brasil.
}

\begin{abstract}
RESUMO: A pandemia mudou abruptamente o processo de trabalho na educação básica, trazendo novos desafios para as redes públicas de ensino. Este artigo apresenta os sentimentos dos professores em meio à pandemia, a partir de um survey realizado com professores das redes públicas de todos os estados do País, e discute sobre o trabalho docente em tempos de pandemia e seus efeitos na saúde mental, em diálogo com a literatura, a partir da hipótese de que a falta de formação, apoio e condições trabalho estão contribuindo para a sobrecarga de trabalho, afetando a saúde mental dos professores.

Palavras-chave: Covid-19. Distanciamento social. Trabalho docente. Saúde mental.
\end{abstract}

\begin{abstract}
The pandemic has abruptly changed the work process in basic education, bringing new challenges to public schools. This article presents the feelings of teachers in the midst of the pandemic, based on
\end{abstract}

* Mestre em Educação e Doutor em Políticas Públicas e Formação Humana. Atualmente é professor da Universidade Federal do Sul da Bahia, onde atua no Centro de Formação em Ciências Humanas e Sociais. E-mail: <gustavo goncalves@cja.ufsb.edu.br>.

* Mestra em Educação pela Universidade Lusófona de Humanidades e Tecnologias e Doutora em Saúde Pública pela Universidade Federal da Bahia. Atualmente é professora da Universidade Federal do Sul da Bahia e professora colaboradora do Instituto de Saúde Coletiva da UFBA. E-mail: <janemg@ufsb.edu.br>. 
a survey carried out with teachers from public schools in every state of the country, and discusses teaching workflow in times of pandemic, and its effects on mental health, in dialogue with literature, based on the hypothesis that the lack of training, support, and working conditions are contributing to work overload, affecting teachers' mental health.

Keywords: Covid-19. Social distancing. Teaching workflow. Mental health.

RESUMEN: La pandemia cambió abruptamente el proceso de trabajo en la educación básica, trayendo nuevos desafíos a las escuelas públicas. Este artículo presenta los sentimientos de los docentes en medio de la pandemia, desde una encuesta realizada con maestros de escuelas públicas de todos los estados del país, y discute la labor docente en tiempos de pandemia y sus efectos en la salud mental, en diálogo con la literatura, partiendo de la hipótesis de que la falta de capacitación, apoyo y condiciones están contribuyendo a la sobrecarga laboral, afectando la salud mental de los docentes.

Palabras clave: Covid-19. Distanciamiento social. Trabajo docente. Salud mental.

\section{Introdução}

pandemia do coronavírus (Covid-19) vem exigindo dos gestores públicos a ado-
ção de medidas para controlar sua disseminação, sendo o distanciamento social
a estratégia mais adotada. Essa medida impactou os sistemas educacionais no mundo, culminando no fechamento das escolas e, consequentemente, no encerramento das aulas presenciais nas instituições de ensino. Posteriormente, a continuidade das atividades de ensino baseou-se em importantes mudanças na forma de organização do trabalho docente: as atividades de ensino presencial passam para a modalidade a distância, visando assim assegurar que a escola continuasse a atender alguns de seus objetivos durante a pandemia. Esta mudança vai exigir uma grande adaptabilidade dos trabalhadores docentes, gerando desafios que foram documentados através da pesquisa Trabalho docente em tempo de pandemia (TDTP) (GESTRADO/CNTE, 2020), que registra os efeitos do distanciamento social e das novas formas de organização do trabalho sobre o trabalhador docente.

Temos como ponto de partida, para refletir sobre os desafios do trabalho docente na pandemia, a dupla função da escola pública de socializar e instruir as crianças. Cabe destacar preliminarmente que no Brasil estas funções são realizadas em condições estruturais 
de funcionamento não ideais, frequentemente atravessadas pela deficiência na infraestrutura, escassez de recursos financeiros e materiais de trabalho (OLIVEIRA; VIEIRA, 2010). Além das funções explícitas, as escolas e os professores têm também uma função importante de proteção ao bem-estar das crianças. Ela é assumida de forma institucional, através de programas amplos como merenda escolar ou programas mais focalizados, como educação em tempo integral, mas repousa sobre as tarefas de cuidado assumidas de forma tácita por docentes, embora este não seja o objetivo expresso de sua função na escola (NORONHA; ASSUNÇÃO; OLIVEIRA, 2008).

As características da escola pública brasileira estão na base das reflexões sobre sua reabertura no contexto de crise atual. A desvalorização do trabalho docente e a vulnerabilidade econômica de parte de seu público são heranças que antecedem a pandemia, contudo, condicionam as respostas a serem dadas a ela. A transferência das atividades de ensino para a modalidade a distância afeta de modo desigual os diferentes grupos de professores bem como as famílias, segundo suas características socioeconômicas ${ }^{1}$.

O fechamento das escolas públicas limita a realização das funções de educar, mas também as funções de proteção social assumidas pelo Estado, gerando aprofundamento de desigualdades sociais. Pensar a continuidade do funcionamento da escola na modalidade a distância apresenta enormes desafios para a regulação do trabalho docente, a desempenhar-se em condições novas, gerando incertezas e ampliando cargas de trabalho e riscos para a saúde mental desses trabalhadores ${ }^{2}$, com consequências para a socialização e instrução dos estudantes.

A mudança nas condições de acesso ao direito à educação para os alunos e a mudança nas condições das práticas docente nas redes públicas de ensino são desafios complexos para os sistemas públicos de ensino e para o trabalhador docente. Visando contribuir para uma análise dos riscos para a saúde mental dos professores responsáveis por dar respostas a estes desafios, busca-se analisar nesse artigo os sentimentos referidos por eles e as estratégias de proteção colocadas em ação pelas redes de ensino.

\section{Percursos metodológicos}

A pesquisa TDTP foi realizada pelo Grupo de Estudos sobre Política Educacional e Trabalho Docente (Gestrado/ UFMG), em parceria com a Confederação Nacional dos Trabalhadores em Educação (CNTE), e colheu entre 8 e 30 de junho de 2020 dados de 15.654 professores, com o objetivo de conhecer os efeitos das medidas de isolamento social, em função da pandemia da Covid-19, sobre o trabalho docente na educação básica nas redes públicas de ensino. A amostra reflete todas as regiões do Brasil e diferentes etapas e modalidades da educação básica. A pesquisa foi protocolada no Comitê de Ética em Pesquisa da Universidade Federal de Minas Gerais (Coep/UFMG). A coleta de dados foi realizada por meio de questionário on-line autoaplicável, disponibilizado na plataforma 
Google Forms. Cabe ponderar que a participação na pesquisa on-line pode ter gerado viés, diante da possibilidade da coleta de dados pré-selecionar respondentes com maior facilidade ou predisposição a envolver-se com atividades on-line.

Este artigo analisa duas questões do questionário que abordaram, respectivamente, os sentimentos dos professores e o suporte emocional e psicológico oferecido pela instituição ao qual estão vinculados. Para realizar a discussão dos resultados foi realizada uma revisão de literatura sobre os efeitos da crise da Covid-19 na saúde mental dos professores.

Organizado em três partes, este estudo inicialmente descreve os resultados das duas questões. Na segunda parte discute o sofrimento dos professores no trabalho, correlacionando os dados referentes à frequência de sentimentos manifestados e os achados na literatura sobre saúde mental e trabalho docente, além de estudos recentes que têm explorado os efeitos da pandemia do coronavírus sobre a saúde dos trabalhadores em educação. Finalmente, na terceira parte, aborda a questão do apoio emocional e psicológico nas instituições de ensino. À guisa de conclusão é apresentada uma síntese e indicações de estratégias para a preservação da saúde mental docente, diante das mudanças no processo de trabalho que tendem a se consolidar.

\section{Sentimentos negativos e necessidade de apoio}

Alguns dados gerais do relatório da pesquisa TDTP (Gestrado/CNTE, 2020) evidenciam o contexto em que os professores participantes do survey estavam atuando em junho de 2020. Cerca de metade estava interagindo com os estudantes, embora o número dos que afirmavam ter facilidade para o uso das TIC fosse muito menor: somente $28,9 \%$ dos respondentes (p.9). Grande proporção de professores sentia que lhe falta habilidades ou capacitação, já que 53,6\% afirmam que não possuem "preparo para ministrar aulas não presenciais" (p.11) o que se soma às identificadas "limitações materiais", pois embora 83\% dos professores possuam "recursos para ministrar aulas não presenciais em casa (...), metade compartilha estes recursos com outras pessoas no domicílio" (p.14).

\section{Sentimento em relação ao trabalho}

Ao responder à questão 1: "Se você pudesse descrever seu sentimento em relação ao seu trabalho neste momento, como seria?", os professores expressaram apenas sentimentos negativos em $86,3 \%$ dos casos. Outros $13,7 \%$ mencionaram o sentimento de “Tranquilidade, tenho certeza de que logo a normalidade será retomada." A questão apresenta cinco alternativas de respostas, cinco sentimentos, sendo os quatro primeiros negativos, e os respondentes poderiam selecionar mais de uma resposta. O sentimento mais presente, selecionado por 7.745 respondentes, foi o "medo e a insegurança por não saber quando e como será o retorno à normalidade." (39,9\% das respostas), seguido do 
sentimento de "angústia em relação ao futuro" (5.016 respostas, selecionado por 32\% dos respondentes) e o sentimento de "Apreensão relacionada à perda de direitos e garantias" (4.335 respostas, selecionado por 27,6\% dos respondentes). "Solidão, em razão do isolamento social" teve uma baixa frequência (125 respostas, selecionado por $0,8 \%$ dos respondentes) (Tabela 1$)$.

\section{Tabela 1: Respostas à questão "Se você pudesse descrever seu sentimento em relação ao seu trabalho neste momento, como seria?"}

\begin{tabular}{|c|c|c|c|c|}
\hline & Sentimentos & $\begin{array}{l}\text { Respostas } \\
\text { selecionadas }\end{array}$ & Respondentes & $\begin{array}{l}\text { Respostas } \\
\text { selecionadas } \\
(\%)\end{array}$ \\
\hline \multirow{4}{*}{ Negativos } & $\begin{array}{l}\text { Angústia em } \\
\text { relação ao futuro. }\end{array}$ & 5.016 & $32,0 \%$ & $25,9 \%$ \\
\hline & $\begin{array}{l}\text { Medo e } \\
\text { insegurança } \\
\text { por não saber } \\
\text { quando e como } \\
\text { será o retorno à } \\
\text { normalidade }\end{array}$ & 7.745 & $49,5 \%$ & $40,0 \%$ \\
\hline & $\begin{array}{l}\text { Apreensão em } \\
\text { relação à perda } \\
\text { de direitos e } \\
\text { garantias. }\end{array}$ & 4.335 & $27,7 \%$ & $22,4 \%$ \\
\hline & $\begin{array}{l}\text { Solidão, em } \\
\text { razão do } \\
\text { isolamento social }\end{array}$ & 125 & $0,8 \%$ & $0,6 \%$ \\
\hline \multirow[t]{2}{*}{ Positivo } & $\begin{array}{l}\text { Tranquilidade, } \\
\text { tenho certeza } \\
\text { de que logo a } \\
\text { normalidade será } \\
\text { retomada }\end{array}$ & 2.146 & $13,7 \%$ & $11,1 \%$ \\
\hline & Total & 19.367 & $123,7 \%$ & $100,0 \%$ \\
\hline
\end{tabular}

Fonte: Pesquisa TDTP (GESTRADO/ CNTE, 2020).

Considerando a amostra de 15.654 professores, observa-se que foram selecionados mais de um sentimento, totalizando 19.367 respostas. Percebe-se que os três sentimentos mais referidos ("medo e insegurança", "angústia" e "apreensão") projetam um futuro de incertezas e instabilidade correlacionados com o estresse. Assume-se, portanto, que os 2.146 professores que afirmaram sentir "tranquilidade" podem sugerir fatores de proteção, merecendo, portanto, um estudo mais detalhado. A seguir comparamos esse grupo, que chamaremos de "tranquilos", com os dados gerais da pesquisa, que englobam todos os respondentes, tentando indicar tendências. 
Os professores são progressivamente menos "tranquilos" na medida em que sucedem as etapas da educação básica, conforme se observa na Tabela 2. Nos anos iniciais do ensino fundamental estão eles levemente sobrerrepresentados em relação aos anos finais, indo de $14 \%$ na educação infantil (portanto acima da média geral de 13,7\%) para $13,9 \%$ nos anos iniciais do ensino fundamental, 13,5\% anos finais do ensino fundamental e 13,3\% no ensino médio. Contrariamente à distribuição destes professores por etapas, não se observa uma diferença significativa na expressão do sentimento de tranquilidade entre às redes municipais e estaduais.

\section{Tabela 2: Respondentes de "tranquilidade" por etapas de ensino}

\begin{tabular}{l|l|l|l}
\hline & $\begin{array}{l}\text { Respondentes } \\
\text { "tranquilidade" }\end{array}$ & Porcentagem & $\begin{array}{l}\text { Participantes da } \\
\text { etapa }\end{array}$ \\
\hline $\begin{array}{l}\text { Educação infantil } \\
\begin{array}{l}\text { Ensino fundamental - } \\
\text { Anos Iniciais }\end{array}\end{array}$ & 455 & $14,0 \%$ & 3.253 \\
\hline $\begin{array}{l}\text { Ensino fundamental - } \\
\text { Anos Finais }\end{array}$ & 727 & $13,9 \%$ & 4.974 \\
\hline Ensino médio & 273 & $13,5 \%$ & 5.370 \\
\hline Total & 2.146 & $13,3 \%$ & 2.057 \\
\hline
\end{tabular}

Fonte: Pesquisa TDTP (GESTRADO/ CNTE, 2020).

Os dados da pesquisa TDTP sugerem que a "experiência anterior ministrando aulas não presenciais (remotas)" correlaciona-se com a frequência do sentimento de "tranquilidade". Embora a frequência média dos professores que têm experiência prévia seja pequena, de apenas 10,1\%, sua distribuição em relação ao sentimento expressado varia. Relacionando os dados apresentados nas tabelas 1 e 3, por um lado, pode-se afirmar que cerca de metade dos professores (49,5\%, Tabela 1) expressaram "medo e insegurança" como sentimento, apesar de 9,5\% destes afirmarem ter experiência prévia com aulas remotas, portanto uma variação de $0,4 \%$ abaixo da média de $10,1 \%$ (Tabela 3). Por outro lado, entre os 13,7\% de professores que expressam "tranquilidade" (Tabela 1), 16\% têm experiência prévia (portanto uma variação de 5,9\% acima da média). Os professores que expressaram o sentimento de "apreensão em relação à perda de direitos e garantias" (27,7\% do total, Tabela 1) são 2,3\% menos frequentes em relação à média daqueles que possuem experiência anterior (7,8\%, Tabela 3). Os dados sugerem, portanto, conforme Tabela 3, que a experiência pode proteger o professor do "medo" e da "insegurança", ao mesmo tempo que favorece seu sentimento de "tranquilidade". 
Tabela 3: Professores que possuem experiência com aulas remotas e seus sentimentos

\begin{tabular}{|l|l|l|l}
\hline & Sentimentos & $\begin{array}{l}\text { Não possuem } \\
\text { experiência }\end{array}$ & $\begin{array}{l}\text { Possuem } \\
\text { experiência }\end{array}$ \\
\hline Negativos & $\begin{array}{l}\text { Angústia em relação ao futuro. } \\
\text { Medo e insegurança por não saber } \\
\text { quando e como será o retorno à } \\
\text { normalidade }\end{array}$ & $89,9 \%$ & $10,1 \%$ \\
\hline $\begin{array}{l}\text { Apreensão em relação à perda de } \\
\text { direitos e garantias. }\end{array}$ & $90,5 \%$ & $9,5 \%$ \\
\hline $\begin{array}{l}\text { Solidão, em razão do isolamento } \\
\text { social }\end{array}$ & $86,4 \%$ & $7,8 \%$ \\
\hline Positivo & $\begin{array}{l}\text { Tranquilidade, tenho certeza de que } \\
\text { logo a normalidade será retomada }\end{array}$ & $84,0 \%$ & $13,6 \%$ \\
\hline & Total & $89,9 \%$ & $16,0 \%$ \\
\hline
\end{tabular}

Fonte: Pesquisa TDTP (GESTRADO/ CNTE, 2020).

Embora as opções de sentimentos oferecidos como possibilidades de respostas na questão 1 sejam reduzidas, a análise dos dados possibilitou correlações que sugerem que as etapas da educação básica são contextos de trabalho que podem influenciar a predisposição e o estado emocional dos trabalhadores docentes de modo diferenciado. A experiência prévia com educação remota também se correlaciona com a ocorrência de sentimentos positivos, como era de se esperar.

\section{Suporte emocional e psicológico}

A segunda questão, formulada como: "com relação a suporte emocional e psicológico, sua instituição tem estado presente?" aborda o apoio institucional aos professores no contexto da pandemia. Os resultados apontam um grande número de respondentes que desconhecem este apoio. Como se observa na Tabela 4, considerando as redes estadual e municipal, 36,4\% (5.635) dos professores responderam que têm apoio, enquanto $63,6 \%$ (9.825) responderam que não. Entretanto, nas redes de ensino estadual este suporte aparece menos presente, identificado por apenas 33,7\% (2.062) dos docentes desta etapa da educação básica.

\section{Tabela 4: Presença da instituição de ensino com relação a suporte emocional e psicológico}




\begin{tabular}{l|l|l|l|l}
\hline & Não & Sim & Total & Sim (\%) \\
\hline Rede Municipal & 5.774 & 3.573 & 9.347 & $38,2 \%$ \\
\hline Rede Estadual & 4.051 & 2.062 & 6.113 & $33,7 \%$ \\
\hline Total & 9.825 & 5.635 & 15.460 & $36,4 \%$ \\
\hline
\end{tabular}

Fonte: Pesquisa TDTP (GESTRADO/ CNTE, 2020).

Os dados da pesquisa sugerem ainda que o apoio oferecido pelas redes de ensino às atividades do professor, na forma de suporte emocional e psicológico, não só está pouco disponível como escasseia quando o professor trabalha remotamente, desde sua casa. Conforme ilustra a Tabela 5, os professores que trabalham na escola são poucos (419) mas são os que contam com maior apoio $(43,9 \%)$. Os professores que realizam atividades de casa são 81,5\% (12.767), dos quais 38\% afirmam que a instituição tem estado presente no suporte emocional e psicológico (4853). Os professores que se encontravam com as atividades suspensas são os que obtinham menos apoio $(34,1 \%)$.

Tabela 5: Suporte emocional e psicológico da instituição segundo oferta de atividades e local de trabalho

\begin{tabular}{l|c|c|c|c}
\hline & Não & Sim & Total & $\begin{array}{l}\text { Apoio } \\
\mathbf{( \% )}\end{array}$ \\
\hline $\begin{array}{l}\text { Não, as atividades escolares foram suspensas, mas } \\
\text { estou interagindo com os estudantes. }\end{array}$ & 749 & 389 & 1.138 & $34,2 \%$ \\
\hline Sim, realizo atividades em casa. & 7.914 & 4.853 & 12.767 & $38,0 \%$ \\
\hline Sim, realizado atividades na escola. & 235 & 184 & 419 & $43,9 \%$ \\
\hline Total & 8.898 & 5.426 & 14.324 & $37,9 \%$ \\
\hline
\end{tabular}

Fonte: Pesquisa TDTP (GESTRADO/ CNTE, 2020).

Como apresenta o relatório Trabalho docente em tempos de pandemia (GESTRADO/ CNTE, 2020), apenas 16,0\% dos(as) professores(as) participantes da pesquisa avaliaram que não houve perdas em relação à participação dos estudantes nas atividades propostas, enquanto 56,1\% afirmam que diminuiu um pouco e 37,7\% afirmam que diminuiu drasticamente. $\mathrm{O}$ ambiente on-line das aulas é desafiador para os alunos, que são pouco autônomos e não têm o adequado suporte das famílias, segundo os professores. No ensino fundamental, $22,3 \%$ dos professores avaliam que os estudantes não possuem autonomia para acompanhar aulas remotas e 39,7\% avaliam que as famílias não conseguem colaborar para garantir a execução das atividades remotas (GESTRADO/ CNTE, 2020). Questões materiais também são uma variável importante para os alunos, como já 
indicado. Considerando "todos os recursos necessários para acompanhar aulas a distância", a pesquisa identificou que 37,8\% dos alunos do ensino fundamental não dispunham desses recursos. Observa-se, portanto, que há uma alta demanda entre os professores que se expressa em incompatibilidade entre a tarefa e os recursos disponíveis para realizá-la, incluindo aqueles dos alunos.

\section{Angústia, medo, insegurança, apreensão e solidão}

Neste tópico é abordado o sofrimento no trabalho docente em contexto de pandemia. Os sentimentos negativos são esperados para um período de pandemia, considerando-os até naturais em um quadro de crise econômica e mudanças estruturais em nível societário. Todavia, além da angústia, medo, insegurança, apreensão e solidão, a pandemia trouxe implicações para a organização familiar, mudanças nas rotinas de trabalho, isolamento, levando a sentimentos de desamparo e abandono (ORNEL et al., 2020; RUSSO; MAGNAN; SOARES, 2020). Como o trabalho docente não ocorre fora da sociedade que o abriga, os professores são afetados por esta crise, desenvolvendo ainda outros sentimentos decorrentes de sua condição própria e desafios da profissão docente no contexto da pandemia. Ramos e colaboradores consideram que a mudança brusca na rotina, associada às incertezas e inseguranças do contexto da pandemia, pode afetar a saúde mental de toda a comunidade escolar. Sugerem a necessidade de novas estratégias de planejamento coletivo amparadas por tecnologias interativas para o fortalecimento de vínculos e a garantia de interações fundamentais para o bem-estar psíquico (RAMOS et al., 2020).

O trabalho docente é identificado como atividade ocupacional fortemente exigente com respeito às cargas mentais e de alta exposição a estressores psicossociais (GASPARINI; BARRETO; ASSUNÇÃO, 2005; CARLOTTO et al., 2015; NORONHA; ASSUNÇÃO; OLIVEIRA, 2008). No contexto pandêmico, o alto investimento afetivo dos professores para responder às demandas da profissão, em condições frequentemente adversas, não produz reconhecimento, mas pode produzir crises de eficácia (CARLOTTO et al., 2015).

Estudos recentes, de caráter exploratório, apontam a necessidade de adaptação das práticas educativas, para atender demandas do ensino remoto, gerando aumento da carga mental dos professores (SILVA et al., 2020; MONTEIRO, SOUZA, 2020; LIMA; DE ARAUJO ABREU, 2020). Um estudo realizado com professores portugueses por Santos (2020) discutiu a utilização de plataformas tipo Zoom para a realização de EaD durante a pandemia, por meio de grupos focais. O resultado consistiu na sistematização dos desafios para o trabalho docente, categorizados em desafios comunicacionais, pedagógicos, sociais e tecnológicos. A exaustão psicológica apresenta-se como consequência de sobrecarga de trabalho, incompatibilidades com a vida pessoal e dificuldade de gerir esses conflitos 
diante da falta de recursos. Dentre os aspectos estudados por Santos (2020) destaca-se a emergência de uma nova relação escola-família. A família se faz mais presente, assumindo papel de apoio pedagógico, porém termina por intervir no processo de trabalho do professor. No ensino a distância os pais podem acessar, julgar e controlar remotamente as ações pedagógicas do professor, sem que novos acordos tenham sido estabelecidos para preservar a autonomia docente.

A exaustão mental é o cúmulo deste processo, quando o trabalho perde o sentido. O esforço solitário para apropriar-se de novas linguagens e plataformas, o confinamento social, o ritmo intensificado de trabalho, a exposição em frente ao computador são fatores que podem contribuir para uma percepção de que o trabalho é vazio, sem conteúdo significativo capaz de alcançar seus objetivos. Uma perda de sentido do trabalho é o que acontece quando a comunicação entre professor e aluno se rompe e um forte desengajamento é percebido na forma de diminuição drástica da participação. Um indício desse desengajamento é a indicação de $46 \%$ dos professores que afirmam ter ocorrido uma pequena diminuição da participação, seguido de $37,7 \%$ dos professores que consideram que houve diminuição drástica da participação dos estudantes nas atividades propostas (GESTRADO/ CNTE, 2020:18).

O sofrimento no trabalho leva a situações frequentemente vividas como "depressão, fadiga, insatisfação, frustração, medo, angústia e ansiedade, até chegar à exaustão" (GASPARINI; BARRETO; ASSUNÇÃO, 2005: 197). Diante do quadro global de fragilização que experimentam trabalhadores, a ausência de motivação pode ser um dos fatores que determina o não investimento no desenvolvimento pessoal, e a autopreservação adquire prioridade para os docentes. A falta de recursos agrava a situação, pois o apoio institucional seria o fator de proteção que permitiria ao professor lidar de modo adequado com essas demandas, contando com colegas e redes de apoio para validar sua competência e trabalhar coletivamente, compartilhando estratégias para realizar as atividades.

\section{Entre o "medo e a tranquilidade"}

Neste tópico são analisados fatores de proteção para a saúde do trabalhador docente no contexto da pandemia, buscando estabelecer indicações para um bem estar docente, diante das mudanças no processo de trabalho que tendem a se consolidar. Como alertam Cepedes (2020) e Lima (2020), é justamente o risco aumentado de desenvolvimento de consequências psicológicas e psiquiátricas na população, em situações de epidemia, o que tem incentivado as universidades e faculdades, sociedades psicanalíticas e grupos de terapeutas voluntários, prestarem apoio aos professores, funcionários técnico-administrativos e estudantes, através do atendimento gratuito na modalidade on-line. A mudança da modalidade de ensino de presencial para a distância, a nova rotina doméstica, a nova rotina de cuidados com a saúde, a perda de amigos e familiares e o medo decorrente das 
condições de trabalho para o retorno às aulas presenciais são algumas das condições que professores de todos os níveis e etapas da educação vêm enfrentando, principalmente aqueles em situação de risco.

Ainda que o ambiente de trabalho das escolas públicas eventualmente possa ser precário, em geral elas dispõem de espaço de convívio entre professores de diferentes áreas e coordenação o que viabiliza o planejamento e o trabalho coletivo (OLIVEIRA; VIEIRA, 2010; OLIVEIRA; VIEIRA, 2012). Este, por sua vez, tem uma importante função para a manutenção e/ou recuperação da saúde dos professores e para a realização dos objetivos do trabalho docente, já que estudos sugerem uma correlação entre trabalho docente coletivo e a proteção ao desgaste do professor. A partir da dados do survey Trabalho docente na educação básica no Brasil (OLIVEIRA; VIEIRA, 2010), Gonçalves e Oliveira (2016) observaram que professores com vozes saudáveis relataram realizar mais "trocas de experiências sobre métodos de ensino", "trocas de experiências sobre conteúdos de ensino", "discussão sobre projeto político-pedagógico da escola" e "discussão sobre alunos e crianças" que professores com problemas de voz, indo ao encontro de outros estudos como Doudin, Curchod-Ruedi e Moreau (2011).

Com o trabalho remoto, as possibilidades de reunião para trocas presenciais são substituídas por um trabalho mais solitário realizado em uma nova rotina no cotidiano doméstico. Há pouca disponibilidade de apoio institucional no contexto da pandemia no Brasil, conforme indicam as tabelas 4 e 5 , as quais revelam um aspecto preocupante: apenas cerca de um terço dos professores recebe apoio da sua rede de ensino em momento de altas demandas e exposição a estressores. Ao contrário do que seria desejável, observa-se maior atomização dos trabalhadores, e professores com medo e inseguros, em isolamento social em suas casas. É compreensível, portanto, que o distanciamento físico e escolas fechadas exponham professores à maior probabilidade de desenvolver problemas de saúde mental. Soma-se a isto problemas de infraestrutura e de formação e um contexto de políticas públicas pouco eficazes na capacitação e acompanhamento para uso das TIC no processo ensino-aprendizagem. Um sentimento protetivo, a tranquilidade, que poderia ser potencializado para promover o envolvimento humanitário, fortalecer grupos e contribuir para desenvolvimento de práticas pedagógicas voltadas para a cooperação (RAMOS et al., 2020) está presente em apenas 11,1\% das respostas.

Nesse contexto, o sindicato emerge como instituição central para fazer o debate político sobre novas formas de produção e condições de trabalho. Conforme sugere Estévez (2020, citado por MORGADO; SOUSA; PACHECO, 2020), o novo normal deve emergir desta crise baseado em uma nova forma de produção e controle social, que, por analogia ao fordismo e ao toyotismo, poderia chamar-se zoomismo, e se define por uma imobilidade produtiva, redução das despesas operacionais e ampla conectividade. Assim, a crise atual não seria derivada de mudança ou crise do trabalho docente, mas de processos sociais 
muito mais amplos sobre os quais as escolhas societárias devem ser feitas de forma esclarecida a partir do debate público.

Um ponto a ser ponderado sobre as mudanças no trabalho docente são as alterações em fatores de risco associados ao adoecimento do trabalhador. A nova forma de produção à distância favorece a posição sentado, o uso de microfone, o fim dos deslocamentos, anulando enfim alguns dos fatores de risco, sobretudo físicos, relacionados à posição em pé e ao uso intenso da voz, identificados no estudo Delcor (2004, citado por GASPARINI; BARRETO; ASSUNÇÃO, 2005). Por outro lado, surgem novos riscos de sofrimento físico e psíquico relacionados ao sedentarismo e ao elevado tempo de trabalho no computador, demandando do trabalhador novas estratégias para mitigá-los. Na medida em que a experiência dos professores aumenta, sugere-se que essas tecnologias para o ensino a distância sejam apropriadas, permitindo incentivar os estudantes a construir um caminho de maior autonomia. O uso dessas tecnologias poderá, então, contribuir para maior autonomia e fortalecimento da educação, com a utilização efetiva desses recursos em uma perspectiva educacional (MENEZES, 2020).

Embora as análises dos dados do survey não permitam um olhar mais focado no nível local, a comunidade escolar e sua inserção territorial são unidades importantes para pensar redes de apoio e fatores de proteção para o trabalho docente. As desigualdades são características do nosso país e marcam a diferença entre unidades educacionais, estudantes e professores em bairros, municípios e estados do Brasil que a pandemia desvelou e ampliou. As estratégias de proteção da saúde devem passar por uma validação em nível local. Considerações sobre a dificuldade de acesso à rede internet e equipamentos informáticos e mesmo sobre ritmo de contaminação pelo COVID-19, que culminam em obstáculos para a reorganização da vida escolar dos estudantes e professores, principalmente da rede pública, precisam ser compreendidas em um nível local. Trata-se de seguir os preceitos da gestão democrática da educação previstos nos artigos 12 e 13 da LDB, o que permite a construção de pactos que protejam igualmente o interesse das famílias e dos trabalhadores docentes.

\section{Conclusão e indicações}

O percurso empreendido para avaliar os riscos para a saúde mental dos professores responsáveis por dar respostas aos desafios da pandemia revelou que há sentimentos negativos como medo e insegurança, consoante com o período de indefinições sobre o exercício da profissão, quando da coleta de dados. $\mathrm{O}$ apoio por parte das instituições para a reorganização da oferta das atividades a distância é necessário. Além disso, as mudanças no trabalho docente exigem grande adaptabilidade dos professores, dentro de um 
contexto em que os meios para as operacionalizar não estão dados. Este quadro sugere grande exposição dos trabalhadores a cargas mentais, com riscos para sua saúde mental.

A infraestrutura das unidades escolares diante do retorno às aulas presenciais é um ponto que merece atenção. Além de garantir os recursos necessários para as atividades pedagógicas, emerge a necessidade de garantir apoio aos professores em suas práticas e para o cuidado de sua saúde mental. O investimento do setor público urge também para garantir a oferta e a participação dos docentes em processos formativos capazes de apoiá-los na construção de novas práticas pedagógicas, consoantes com as mudanças nas condições de trabalho, considerando cada realidade local. Por fim, apoiar os professores, por um lado, para garantir e/ou reestabelecer sua saúde mental; por outro, por compreender que são eles os conhecedores de suas possibilidades e limites, bem como as de seus estudantes.

Emerge a necessidade de pensar políticas negociadas e construídas a partir de um coletivo que considere as experiências singulares, de experiências comunitárias e enraizadas em um nível local do território, evitando a generalização sobre o que é saúde, o que é risco e o que é cuidado.

Recebido em: 14/10/2020 e Aprovado em: 30/10/2020

\section{Notas}

1 O Instituto de Pesquisa Econômica Aplicada (Ipea), através de Nota técnica sobre o Acesso domiciliar à internet e ensino remoto durante a pandemia, constatou, com base em dados do Pnad, do Inep, entre outros, que, no Brasil, do total de 27,2 milhões de matrículas no ensino fundamental em 2018, entre 4,3 e 4,4 milhões, ou seja, aproximadamente $16 \%$, não dispunham de acesso domiciliar à internet em banda larga ou $3 \mathrm{G} / 4 \mathrm{G}$ para a realização das atividades remotas de ensino-aprendizagem, sendo a maioria dos estudantes sem acesso das redes públicas de ensino (NASCIMENTO et al., 2020).

2 OMinistério Público do Trabalho emitiu Nota Técnica (MPT, 2020) para garantir a proteção da saúde e direitos fundamentais de professores no exercício de suas atividades laborais, através de plataformas virtuais e/ou em home office. Na nota, entre outras responsabilidades, atribui aos estabelecimentos de ensino a aquisição, manutenção de equipamentos e infraestrutura do trabalho remoto e reembolso de eventuais despesas; observação dos parâmetros de ergonomia física e condições de trabalho, equipamentos, mesas, cadeiras, a postura física, oferecendo ou reembolsando os valores desses bens; orientações sobre exercícios de ginástica laboral, que objetivem evitar lesões; e, devido ao maior desgaste psicossomático na ministração de aulas por meios virtuais, a adequação na distribuição das atividades e dos tempos de trabalho.

\section{Referências}

CARLOTTO, M. S. et al. O papel mediador da autoeficácia na relação entre a sobrecarga de trabalho e as dimensões de Burnout em professores. Psico-usf, [s.1.], v. 20, n. 1, p.13-23, abr. 2015. Disponível em https:// 
www.scielo.br/scielo.php?script=sci_arttext\&pid=S1413-82712015000100003 acesso em 29 de setembro de 2020.

CEPEDES - Centro de estudos e pesquisas em emergências e desastres em saúde; Fundação Oswaldo Cruz. Saúde mental e Atenção Psicossocial na Pandemia COVID-19: Recomendações gerais. Brasília, 2020.

DOUDIN, P. A.; CURCHOD-RUEDI, D.; MOREAU, J. Le soutien social comme facteur de protection de l'épuisement des enseignants. Em: DOUDIN, P. A. et al. La santé psychosociale des enseignants et des enseignantes. Québec: Presses de l’Université de Québec, 2011. p. 11-38.

GASPARINI, S.M.; BARRETO, S.M.; ASSUNÇÃO, A.A. O professor, as condições de trabalho e os efeitos sobre sua saúde. Educação e Pesquisa. São Paulo, v.31, n.2, p. 189-199, mai/ago. 2005.

GESTRADO/ CNTE. Trabalho docente em tempos de pandemia (Relatório técnico). 2020. Disponível em <http:// abet-trabalho.org.br/relatorio-tecnico-trabalho-docente-em-tempos-de-pandemia $>$. Acesso em 28/09/2020.

GONÇALVES, G.B.B.; OLIVEIRA, D.A. Saúde vocal e condições de trabalho na percepção dos docentes de educação básica. Revista da FAEEBA - Educação e Contemporaneidade, Salvador, v.25, n.46, p.89-104, maio/ago 2016.

LIMA, N. S.; DE ARAÚJO ABREU, Carlos Tibúrcio. Saúde mental de docentes universitários. Physis: Revista de Saúde Coletiva, Rio de Janeiro, v. 30, n. 2, p. e300216, 2020.

LIMA, R. C.. Distanciamento e isolamento sociais pela Covid-19 no Brasil: impactos na saúde mental. Physis: Revista de Saúde Coletiva, Rio de Janeiro, v. 30, p. e300214, 2020.

MENEZES, G. G. de. A utilização das TIC nos processos de formação continuada e o envolvimento dos professores em comunidades de prática. Educar em revista, Curitiba, n. 51, p. 283-299, 2014.

MINISTÉRIO PÚBLICO DO TRABALHO. Nota Téctica - Gt Covid 19 - 11/2020. Disponível em: https:// mpt.mp.br/pgt/noticias/nota-tecnica-n-11-2020-trabalho-on-line-de-professores-gt-covid-19-mpt.pdf. Acesso em 10 de outubro de 2020.

MONTEIRO, B. M. M.; SOUZA, J. C.. Saúde mental e condições de trabalho docente universitário na pandemia da COVID-19. Research, Society and Development, Itajubá, v. 9, n. 9, e468997660-e468997660, 2020.

MORGADO, J. C.; SOUSA, J.; PACHECO, J. A. Transformações educativas em tempos de pandemia: do confinamento social ao isolamento curricular. Práxis Educativa, Ponta Grossa v. 15, p. 1-10, 2020.

NASCIMENTO, Paulo Meyer et al. Nota Técnica n. 88 (Disoc) : Acesso domiciliar à internet e ensino remoto durante a pandemia. IPEA, 2020. Disponível em: http://repositorio.ipea.gov.br/ handle/11058/10228. Acesso 10 de outubro de 2020

NORONHA, M.M.B.; ASSUNÇÃO, A.A.; OLIVEIRA, D.A. O sofrimento no trabalho docente: o caso das professoras da rede pública de Montes Claros, Minas Gerais. Trab. educ. saúde, Rio de Janeiro, v. 6, n. 1, mar.jjun. 2008.

OLIVEIRA, D. A.; VIEIRA, L. F. (Orgs.) Trabalho docente na educação básica: a condição docente em sete estados brasileiros. Belo Horizonte: Fino Traço, 2012.

OLIVEIRA, D. A.; VIEIRA, L. M. F. Trabalho docente na educação básica no Brasil. Base de Dados TDEBB/ GESTRADO. Faculdade de Educação/UFMG. Belo Horizonte, 2010.

ORNELL, F. et al. "Pandemic fear" and COVID-19: mental health burden and strategies. Brazilian Journal of Psychiatry, São Paulo, v. 42, n. 3, p. 232-235, 2020. 
PEREIRA, H. P.; SANTOS, F. V.; MANENTI, M. A.. Saúde mental de docentes em tempos de pandemia: os impactos das atividades remotas. Boletim de Conjuntura (BOCA), Boa Vista, v. 3, n. 9, p. 26-32, 2020.

RAMOS, C. E. P. L. et al. O bem-estar subjetivo da comunidade estudantil do IFB em tempos de pandemia. Brasília: IFB, 2020.

RUSSO, K. ; MAGNAN, M.O.; SOARES, R. A pandemia que amplia as desigualdades: a Covid-19 e o sistema educativo de Quebec/Canadá. Praxis Educativa, Ponta Grossa, v.15, e201591, 2020.

SANTOS, H. M. R.; Os desafios de educar através da Zoom em contexto de pandemia: investigando as experiências e perspetivas dos docentes portugueses. Praxis Educativa, Ponta Grossa, v. 15, e2015805, 2020.

SILVA, A. F. da et al. Saúde mental de docentes universitários em tempos de pandemia. Physis: Revista de Saúde Coletiva, Rio de Janeiro, v. 30, e300216, 2020. 